Research Paper

\title{
Human Papillomavirus Type 16 El Mutations Associated with Cervical Cancer in a Han Chinese Population
}

\author{
Yueting Yao ${ }^{*}$, Zhiling Yan ${ }^{2}$, Shuying Dai ${ }^{3}$, Chuanyin Li ${ }^{1}$, Longyu Yang1, Shuyuan Liu ${ }^{1}$, Xinwen Zhang1, Li \\ Shi ${ }^{\circledR}$, Yufeng Yao ${ }^{\boxplus}$ \\ 1. Institute of Medical Biology, Chinese Academy of Medical Sciences \& Peking Union Medical College, Kunming 650118, Yunnan, China \\ 2. Department of Gynaecologic Oncology, The 3rd Affiliated Hospital of Kunming Medical University, Kunming 650118, China. \\ 3. School of Basic Medical Science, Kunming Medical University, Kunming 650500, China. \\ *These authors contributed equally to this work.
}

$\square$ Corresponding authors: Prof. Li Shi shili.imb@gmail.com and/or Prof. Yufeng Yao Email leoyyf@gmail.com Institute of Medical Biology, Chinese Academy of Medical Sciences \& Peking Union Medical College, Kunming 650118, Yunnan, China.

(1) The author(s). This is an open access article distributed under the terms of the Creative Commons Attribution License (https://creativecommons.org/licenses/by/4.0/). See http://ivyspring.com/terms for full terms and conditions.

Received: 2019.02.20; Accepted: 2019.05.30; Published: 2019.06.24

\begin{abstract}
Human papillomavirus type 16 (HPV16) is a high-risk HPV type and a potent carcinogen. HPV El is one of the most highly conserved proteins and it plays a central role in initiating HPV DNA replication. In current study, we enrolled 161 HPV16-positive cervical cancer patients (case group) and 171 HPV16-positive asymptomatic individuals (control group) in a study to analyse the association between HPV16 El genetic mutations and cervical cancer. The samples of case group were cervical cancer tissues and the samples of control group were cervical exfoliated cells. Three variants (A4, Al-A3 and D3) were found in the case group, $68.3 \%$ of the HPV16 El sequences belonged to the $A 4$ (As) sub-lineage, $29.2 \%$ belonged to the $A 1-A 3$ (EUR) sub-lineage, and $2.5 \%$ belonged to the $D 3$ (AA1) sub-lineage. Two variants (A4 and A1-A3) occurred in the control group. The A4 (As) sub-lineage was predominant in this group as well (66.1\%), followed by the Al-A3 (EUR) sub-lineage (33.9\%), but the D3 (AAl) sub-lineage was not found in the control group. The distribution of the HPV16 variants between the case and control groups was significantly different $(P<0.05)$. When the distribution of the HPV16 El gene mutations was compared, the distribution of twenty-seven mutations was significantly different between the case and control groups $(P<0.05)$, and twenty-two mutations occurred only in the D3 (AA1) sub-lineage, two were found only in the A4 (As) sub-lineage, one was found in the Al-A3 (EUR) sub-lineage, two was found in both the A4 (As) and A1-A3 (EUR) sub-lineages. In the sub-lineage analysis, the differences in the T933A (A23A), T1014G (D50E) and G2160A (R432R) mutations were statistically significant between the case and control groups for the $A 4(A s)$ sub-lineage $(P<0.05)$, and the differences in the T2232C (F456F), G2337A (M491I) and A2547G (P561P) mutations were statistically significant between the case and control groups for the A1-A3 (EUR) sub-lineage $(P<0.05)$. In the current study, we describe specific mutations in the HPV16 El gene associated with cervical cancer, and our study will provide a good reference for further functional studies of the relationship between cervical cancer carcinogenesis and HPV genes.
\end{abstract}

Key words: Human papillomavirus type 16 (HPV16); E1 gene; Cervical cancer; Mutations; Association study

\section{Introduction}

Cervical cancer is one of the most common malignancies in females. The major factor contributing to the development of cervical cancer is persistent infection with high-risk human papillomaviruses (HPVs) [1, 2]. HPVs could be divided into low risk and high-risk types. Low risk HPVs are associated with $90 \%$ genital warts and also related to the development of recurrent respiratory papillomatosis, including HPV6 and HPV11 [3-5]. High-risk HPVs are frequently associated with 
cervical cancer and approximately $15 \mathrm{HPV}$ genotypes (HPV16, 18, 31, 33, 35, 39, 45, 51, 52, 56, 58, 59, 68, 73, and 82) are recognized as high-risk types according to an epidemiological survey [6]. Among these high-risk types, HPV16 is the most common type detected in patients with cervical cancer worldwide and a prospective cohort study showed that it was also the most persistent HPV type during infection with HPVs $[7,8]$. In addition, HPV16 also thought to be associated with head and neck squamous cells carcinomas $[9,10]$.

The HPV16 genome is a circular, double-stranded 7,908 bp molecule and is divided into three major regions: the early region, encoding viral early proteins, compring the E1, E2, E4, E5, E6 and E7 genes; the late region, encoding the viral late proteins L1 and L2; and the long control region (LCR), which includes the viral transcription control sequence and the replication sequence [11]. HPV E1 and E2 are necessary for viral replication. The E1 protein recognizes and binds to an AT-rich sequence within the viral DNA origin of replication in cooperation with the E2 protein and the complex composed of the E1 and E2 proteins then binds to the viral origin of replication with high affinity and initiates DNA replication via the E1 ATP-dependent helicase domain [12]. Furthermore, the E1 helicase domain interacts with DNA polymerase a-primase, topoisomerase I and the single-stranded DNAbinding protein RPA to recruit cellular replication factors to the viral origin of replication, thus forming an active replication complex [13-16]. In 2017, Baedyananda et al. reported that the high expression of HPV16 E1 is associated with cervical cancer progression [17]. Furthermore, in 2014, Tsakogiannis et al. reported that the A1668G, G2073A, T2169C, T2189C, A2453T, C2454T, A2587T and G2650A mutations of HPV16 E1 were identified only in high-grade dysplasia cases in a Greek population [14], and this result indicated that those mutations may play an important role in cervical carcinogenesis.

Several studies have reported that the distribution of HPV16 variants is different in different regions and ethnicities [18-21]. For example, the A1-A3 (European, EUR) is the predominant variant in the Greek population [18-20], but the A4 (Asian, As) is the predominant variant in the Han Chinese population [21]. Thus, in the present study, we aimed to identify HPV16 E1 mutations in HPV16-positive asymptomatic individuals and HPV16-positive cervical cancer patients and then to evaluate the association of HPV16 E1 mutations with cervical cancer in a Han Chinese population.

\section{Materials and methods}

\section{Subjects}

In the present study, the case group included 161 samples of cervical cancer tissue were gathered from HPV16-positive cervical cancer patients, and 171 samples of cervical exfoliated cells were gathered by fluidbase brush sampling and aseptic cotton sampling from HPV16-positive asymptomatic individuals undergoing routine health check-ups were recruited as the control group. All individuals were recruited at the 3rd Affiliated Hospital of Kunming Medical University during the years 2013 to 2017. The diagnosis of cervical cancer was confirmed by pathological examination according to CURRENT Diagnosis \& Treatment Obstetrics \& Gynecology and FIGO stage (International Federation of Gynaecology and Obstetrics, 2009). Subjects with oncotherapy histories and other malignancies or incomplete clinical data were excluded from the present study. The inclusion criteria for the HPV16-positive asymptomatic individuals were HPV16-positive status, female, and the absence of cervical lesions. All participants were self-reported as ethnically Han and settled in Yunnan for a long time in this study.

\section{HPV genotyping}

For HPV genotyping, the Tellgenplex ${ }^{\mathrm{TM}} \mathrm{HPV}$ DNA Test which is a suspension bead array method for identifying HPV types was used. The experimental protocol has been described in a previous study [22]. Human $\beta$-globin was used as an internal control for each reaction.

\section{Amplification and sequencing of the HPVI6 EI gene}

The HPV16 E1 gene was amplified using a high-fidelity DNA polymerase with the primers 5'-GGACAAGCAGAACCGGA-3' and 5'-CGTCTTGTAATGTCCACTTTTC-3' (2357 bp). The PCR product contained the complete E1 sequence with a length of $1950 \mathrm{bp}$. The PCR reactions were performed in a final volume of $25 \mu \mathrm{l}$ and each PCR mixture contained $1 \times$ Q5 PCR buffer (containing $\mathrm{Mg} 2+), 200 \mu \mathrm{M}$ dNTPs, $0.5 \mu \mathrm{M}$ sense and antisense primers, $50 \mathrm{ng}$ genomic DNA, and $0.02 \mathrm{U} / \mu \mathrm{l}$ high-fidelity DNA polymerase. The PCR conditions were as follows: an initial denaturation step at $98^{\circ} \mathrm{C}$ for $3 \mathrm{~min}, 35$ cycles of denaturation at $98^{\circ} \mathrm{C}$ for $10 \mathrm{~s}$, annealing at $64^{\circ} \mathrm{C}$ for $30 \mathrm{~s}$, and extension at $72^{\circ} \mathrm{C}$ for 90 $\mathrm{s}$, and a final elongation at $72^{\circ} \mathrm{C}$ for $2 \mathrm{~min}$. The amplified DNA fragments (including the complete E1 gene) were sent to Shanghai Sangon Biotech for sequencing after visualization with a $1.0 \%$ agarose electrophoresis assay. The primers used for E1 gene 
sequencing were 5'-GGACAAGCAGAACCGGA-3', 5'-GCAATTTCACTATCGTCTACTATG-3', 5'-CCAA TGCATTTCTTAAATTGTC-3', and 5'-CGTCTTGTA ATGTCCACTTTTC-3'.

\section{Identification and phylogenetic analyses of HPV16 El gene variants}

All of the sequences of the HPV16 E1 sequences were assembled by SeqMan software and aligned by the ClustalW multiple sequence alignment tools included in the Molecular Evolutionary Genetics Analysis (MEGA) v7.0 software package. The HPV16 reference sequence K02718.1 was used to identify mutations in the HPV16 E1 sequences. Phylogenetic trees of the HPV16 E1 gene were constructed using MEGA 7.0 software by the Maximum likelihood method by bootstrapping with 1000 replications. The reference sequences used to construct the phylogenetic tree were obtained from GenBank, and the accession numbers were HQ644283.1 (A1), HQ644268.1 (A1), HQ644280.1 (A1), HQ644282.1 (A1), AF536179.1 (A2), HQ644236.1 (A3), HQ644248.1 (A4), HQ644251.1 (A4), AF534061.1 (A4), HQ644235.1 (A4), HQ644240.1 (B1), HQ644290.1 (B1), HQ644238.1 (B1), HQ644298.1 (B3), HQ644237.1 (C), HQ644239.1 (C), HQ644249.1 (C), HQ644250.1 (C), AF472509.1 (C), HQ644257.1 (D1), HQ644279.1 (D2), HQ644281.1 (D2), HQ644263.1 (D2), HQ644277.1 (D2), HQ644247.1 (D3), HQ644253.1 (D3), HQ644255.1 (D3), AF402678.1 (D3).

\section{Statistical analysis}

The Student's t-test was used to compare the age distribution between the case and control groups. The frequency of each HPV16 E1 gene mutation was determined by direct counting. A chi-squared test was performed to analyse the associations among HPV16 variants, HPV16 E1 mutations and cervical cancer. The statistical analyses were performed using SPSS 13 (Chicago, IL), and $P$ values that are less than 0.05 were considered statistically significant.

\section{Results}

\section{Subject characteristics}

In current study, all participants were female, self-reported as ethnically Han and lived in Yunnan for a long time. The case group included 161 HPV16-positive cervical cancer patients and all of them belonged to squamous cell carcinoma (SCC), the age distribution was $46.14 \pm 10.14$ (mean \pm SD). The control group included 171 HPV16-positive asymptomatic individuals, the age distribution was $46.96 \pm 9.17$ (mean $\pm \mathrm{SD}$ ). There was no significant difference in age between the case and control group $(P=0.435)$.

\section{Distribution of HPV16 variants in the case and control groups}

HPV16 variants can be divided into four phylogenetic lineages (A, B, C and D) and 16 sub-lineages: A1-A3 (previously known as EUR variant), A4 (As variant), B1-B4 (AFR1 variant), C1-C4 (AFR2 variant), D1 (NA variant), D2 (AA2 variant), D3 (AA1 variant) and D4. In the current study, the phylogenetic tree constructed by the Maximum likelihood showed the divergence of the HPV16 sub-lineages clearly (Supplementary Figure 1 and 2). There were three HPV16 variants in the case group, namely, A4 (As), A1-A3 (EUR) and D3 (AA1) with distribution frequencies of $68.3 \%, 29.2 \%$ and $2.5 \%$, respectively. However, in the control group, only A4 (As) and A1-A3 (EUR) sub-lineages were found with distribution frequencies of $66.1 \%$ and $33.9 \%$. The difference in the distribution of the HPV16 variants between the case group and control group was statistically significant $(P=0.045)$.

\section{HPV16 El gene mutations in the case and control groups}

The HPV16 E1 gene mutations in the case and control groups were shown in Supplementary Table 1; the reference sequence used was K02718.1. In the case group, forty-nine mutations were observed; twenty of these were non-synonymous mutations, and the remaining twenty-nine were synonymous. Moreover, the T921C (T19T), T933A (A23A), T1014G (D50E), A1041G (L59L), C1096G (Q78E), G1163A (G100E), T1200C (A112A), T1366A (C168S), T1407G (S181R), C1426G (Q188E), T1486C (L208L), T1522A (S220T), C1624T (L154L), A1668G (A268A), C1744A (L294M), C2041T (L393L), G2220C (E452D), T2232C (F456F), C2237G (T458S), G2249A (R462K), C2262T (G466G), C2287T (L475L), T2567G (I568S), T2586C (S574S), A2608C (R582R), T2631A (P589P) and G2650A (E596K) mutations were found only in the case group. In the control group, 171 HPV16-positive asymptomatic individuals were accepted into this study. Thirty-one mutations were detected in the control group; nine of these were non-synonymous, and twenty-two were synonymous. Furthermore, the C878A (A5E), T969C (D35D), T1152C (S96S), A1395T (G177G), T1447G (L195V), T1602C (S246S), T2040C (F392F), A2535C (L557L) and A2547G (P561P) mutations were found only in the control group. We found twenty-seven mutations that were statistically significant when the genetic mutation distribution was compared between the case group and control group, and these mutations comprised eleven non-synonymous mutations and sixteen synonymous mutations. Among these mutations, T921C (T19T), A1041G (L59L), C1096G (Q78E), G1163A (G100E), 
T1200C (A112A), T1366A (C168S), C1426G (Q188E), T1486C (L208L), T1522A (S220T), C1624T (L154L), A1668G (A268A), C1744A (L294M), C2041T (L393L), G2220C (E452D), C2237G (T458S), G2249A (R462K), C2262T (G466G), C2287T (L475L), T2586C (S574S), A2608C (R582R), T2631A (P589P) and G2650A (E596K) were found only in the HPV16 D3 (AA1) sub-lineage; T933A (A23A) and T1014G (D50E) were observed only in the A4 (As) sub-lineage; A2547G (P561P) was found only in the A1-A3 (EUR) sub-lineage; G2160A (R432R) and T2232C(F456F) was found in both the A4 (As) and A1-A3 (EUR) sub-lineages.

\section{Distribution of HPV16 El gene mutations in the A4 (As), A1-A3 (EUR) and D3 (AA1) sub-lineages}

In the HPV16 A4 (As) sub-lineage, fifteen mutations were found in the case group and twelve mutations were found in the control group during the analysis of those sequences. In the case group, seven mutations were non-synonymous and eight mutations were synonymous. In the control group, five mutations were non-synonymous and seven mutations were synonymous. The distributions of the T933A (A23A), T1014G (D50E) and G2160A (R432R) mutations were significantly different between the case and control group for the A4 (As) sub-lineage (Table 1). In the analysis of the A1-A3 (EUR) sub-lineage, a total of fifteen mutations were observed in the case group, among which are five non-synonymous mutations and ten synonymous mutations. In addition, a total of twenty-five mutations were found in the control group, eight of these were non-synonymous and seventeen were synonymous. In the comparison of the distribution of these mutations between the case and control groups, we found that the distributions of the T2232C (F456F), G2337A (M491I) and A2547G (P561P) mutations were significantly different $(P<0.05)$ (Table 2$)$. For the D3 (AA1) sub-lineage, which occurred only in the case group, a total of twenty-eight mutations with a frequency of $100 \%$ were found; except for T1139G (V92G), C1377T (Y171Y), A1842G (I326M), T2254C (L464L), T2343C (F493F) and C2344T (L494L), these mutations occurred only in the D3 (AA1) sub-lineage. Of these mutations, twelve were non-synonymous (Table 3).

\section{Discussion}

Among all HPV16 proteins, HPV16 E1 is the only protein acting as an enzyme for initiating the replication of the viral genome inside host cells [12]. Previous studies found that the E1 protein may also play an important role in mitigating the host's ability to defend against viral infection [23]. In the present study, we analysed the distribution of different variants, nucleotide sequence mutations and amino acid substitutions in the HPV16 E1 gene between HPV16-positive cervical cancer patients and HPV16-positive asymptomatic individuals in a Chinese Han population in order to identify some mutations related to cervical cancer.

Table 1. HPV16 El gene mutations and amino acid substitutions in the A4 (As) sub-lineage in the case and control groups.

\begin{tabular}{|c|c|c|c|c|c|c|c|c|c|c|c|}
\hline \multirow{2}{*}{$\begin{array}{l}\text { Genome } \\
\text { position a }\end{array}$} & \multicolumn{2}{|c|}{ Case $(n=110)$} & \multicolumn{2}{|c|}{ Control $(n=113)$} & \multirow{2}{*}{$\begin{array}{l}P \\
\text { Value* }^{*}\end{array}$} & \multirow{2}{*}{$\begin{array}{l}\text { Amino } \\
\text { acid a }^{\circ}\end{array}$} & \multicolumn{2}{|c|}{ Case $(n=110)$} & \multicolumn{2}{|c|}{ Control $(n=113)$} & \multirow{2}{*}{$\begin{array}{l}P \\
- \text { Value }^{*}\end{array}$} \\
\hline & Mutation & Frequency (\%) & Mutation & Frequency (\%) & & & Mutation & Frequency (\%) & Mutation & Frequency (\%) & \\
\hline T933A & 4 & 3.6 & 0 & 0.0 & 0.041 & A23A & 0 & 0.0 & 0 & 0.0 & - \\
\hline T1014G & 4 & 3.6 & 0 & 0.0 & 0.041 & D50E & 4 & 3.6 & 0 & 0.0 & 0.041 \\
\hline T1139G & 110 & 100.0 & 113 & 100.0 & - & V92G & 110 & 100.0 & 113 & 100.0 & - \\
\hline $\mathrm{C} 1377 \mathrm{~T}$ & 11 & 10.0 & 12 & 10.6 & 0.879 & Y171Y & 0 & 0.0 & 0 & 0.0 & - \\
\hline A1395T & 0 & 0.0 & 2 & 1.8 & 0.161 & G177G & 0 & 0.0 & 0 & 0.0 & - \\
\hline T1407G & 3 & 2.7 & 0 & 0.0 & 0.077 & S181R & 3 & 2.7 & 0 & 0.0 & 0.077 \\
\hline T1447G & 0 & 0.0 & 1 & 0.9 & 0.323 & L195V & 0 & 0.0 & 1 & 0.9 & 0.323 \\
\hline G1515A & 110 & 100.0 & 113 & 100.0 & - & V217V & 0 & 0.0 & 0 & 0.0 & - \\
\hline T1643C & 6 & 5.5 & 4 & 3.5 & 0.490 & L260S & 6 & 5.5 & 4 & 3.5 & 0.490 \\
\hline A1842G & 110 & 100.0 & 113 & 100.0 & - & $\mathrm{I} 326 \mathrm{M}$ & 110 & 100.0 & 113 & 100.0 & - \\
\hline G2160A & 9 & 8.2 & 26 & 23.0 & 0.002 & R432R & 0 & 0.0 & 0 & 0.0 & - \\
\hline T2200C & 6 & 5.5 & 4 & 3.5 & 0.490 & L446L & 0 & 0.0 & 0 & 0.0 & - \\
\hline T2232C & 1 & 0.9 & 0 & 0.0 & 0.310 & $\mathrm{~F} 456 \mathrm{~F}$ & 0 & 0.0 & 0 & 0.0 & - \\
\hline $\mathrm{T} 2254 \mathrm{C}$ & 19 & 17.3 & 16 & 14.2 & 0.523 & L464L & 0 & 0.0 & 0 & 0.0 & - \\
\hline G2337A & 110 & 100.0 & 113 & 100.0 & - & $\mathrm{I} 491 \mathrm{M}$ & 110 & 100.0 & 113 & 100.0 & - \\
\hline A2439C & 11 & 10.0 & 12 & 10.6 & 0.879 & $\mathrm{~T} 525 \mathrm{~T}$ & 0 & 0.0 & 0 & 0.0 & - \\
\hline T2567G & 3 & 2.7 & 0 & 0.0 & 0.077 & I568S & 3 & 2.7 & 0 & 0.0 & 0.077 \\
\hline
\end{tabular}

a The reference HPV16 E1 sequence used was K02718.1

${ }^{*} P$ values less than 0.05 were considered statistically significant. 
Table 2. HPV16 El gene mutations and amino acid substitutions in the Al-A3 (EUR) sub-lineage in the case and control groups.

\begin{tabular}{|c|c|c|c|c|c|c|c|c|c|c|c|}
\hline \multirow{2}{*}{$\begin{array}{l}\text { Genome } \\
\text { position }\end{array}$} & \multicolumn{2}{|c|}{ Case $(n=47)$} & \multicolumn{2}{|c|}{ Control $(n=58)$} & \multirow{2}{*}{$\begin{array}{l}P \\
\text { Value* }\end{array}$} & \multirow{2}{*}{$\begin{array}{l}\text { Amino } \\
\text { acid a }^{\circ}\end{array}$} & \multicolumn{2}{|c|}{ Case $(n=47)$} & \multicolumn{2}{|c|}{ Control $(n=58)$} & \multirow{2}{*}{$\begin{array}{l}P \\
\text { Value*}^{*}\end{array}$} \\
\hline & Mutation & Frequency (\%) & Mutation & Frequency (\%) & & & Mutation & Frequency (\%) & Mutation & Frequency (\%) & \\
\hline C878A & 0 & 0.0 & 3 & 5.2 & 0.114 & A5E & 0 & 0.0 & 3 & 5.2 & 0.114 \\
\hline T969C & 0 & 0.0 & 2 & 3.4 & 0.199 & D35D & 0 & 0.0 & 0 & 0.0 & - \\
\hline T1139G & 47 & 100.0 & 58 & 100.0 & - & V92G & 47 & 100.0 & 58 & 100.0 & - \\
\hline T1152C & 0 & 0.0 & 3 & 5.2 & 0.114 & S96S & 0 & 0.0 & 0 & 0.0 & - \\
\hline T1421C & 4 & 8.5 & 4 & 6.9 & 0.757 & I186T & 4 & 8.5 & 4 & 6.9 & 0.757 \\
\hline T1447G & 0 & 0.0 & 1 & 1.7 & 0.366 & L195V & 0 & 0.0 & 1 & 1.7 & 0.366 \\
\hline G1515A & 4 & 8.5 & 4 & 6.9 & 0.757 & V217V & 0 & 0.0 & 0 & 0.0 & - \\
\hline T1602C & 0 & 0.0 & 2 & 3.4 & 0.199 & S246S & 0 & 0.0 & 0 & 0.0 & - \\
\hline A1634C & 4 & 8.5 & 2 & 3.4 & 0.266 & Q257P & 4 & 8.5 & 2 & 3.4 & 0.266 \\
\hline A1842G & 14 & 29.8 & 10 & 17.2 & 0.128 & $\mathrm{I} 326 \mathrm{M}$ & 14 & 29.8 & 10 & 17.2 & 0.128 \\
\hline A1932C & 28 & 59.6 & 42 & 72.4 & 0.165 & E356D & 28 & 59.6 & 42 & 72.4 & 0.165 \\
\hline G1941A & 4 & 8.5 & 2 & 3.4 & 0.266 & Q359Q & 0 & 0.0 & 0 & 0.0 & - \\
\hline T2019C & 4 & 8.5 & 2 & 3.4 & 0.266 & T385T & 0 & 0.0 & 0 & 0.0 & - \\
\hline T2040C & 0 & 0.0 & 2 & 3.4 & 0.199 & F392F & 0 & 0.0 & 0 & 0.0 & - \\
\hline A2158C & 6 & 12.8 & 5 & 8.6 & 0.490 & R432R & 0 & 0.0 & 0 & 0.0 & - \\
\hline G2160A & 0 & 0.0 & 1 & 1.7 & 0.366 & R432R & 0 & 0.0 & 0 & 0.0 & - \\
\hline $\mathrm{T} 2232 \mathrm{C}$ & 4 & 8.5 & 0 & 0.0 & 0.023 & $\mathrm{~F} 456 \mathrm{~F}$ & 0 & 0.0 & 0 & 0.0 & - \\
\hline T2233C & 6 & 12.8 & 5 & 8.6 & 0.490 & L457L & 0 & 0.0 & 0 & 0.0 & - \\
\hline $\mathrm{T} 2301 \mathrm{C}$ & 16 & 34.0 & 19 & 32.8 & 0.890 & A479A & 0 & 0.0 & 0 & 0.0 & - \\
\hline G2337A & 0 & 0.0 & 6 & 10.3 & 0.023 & M491I & 0 & 0.0 & 6 & 10.3 & 0.023 \\
\hline T2343C & 0 & 0.0 & 2 & 3.4 & 0.199 & F493F & 0 & 0.0 & 0 & 0.0 & - \\
\hline C2344T & 5 & 10.6 & 9 & 15.5 & 0.465 & L494L & 0 & 0.0 & 0 & 0.0 & - \\
\hline T2376G & 17 & 36.2 & 19 & 32.8 & 0.714 & S504S & 0 & 0.0 & 0 & 0.0 & - \\
\hline A2535C & 0 & 0.0 & 2 & 3.4 & 0.199 & L557L & 0 & 0.0 & 0 & 0.0 & - \\
\hline A2547G & 0 & 0.0 & 7 & 12.1 & 0.014 & P561P & 0 & 0.0 & 0 & 0.0 & - \\
\hline T2595G & 17 & 36.2 & 19 & 32.8 & 0.714 & P577P & 0 & 0.0 & 0 & 0.0 & - \\
\hline
\end{tabular}

a The reference HPV16 E1 sequence used was K02718.1

${ }^{*} P$ values less than 0.05 were considered statistically significant.

Table 3. HPV16 El gene mutations and amino acid substitutions in the $\mathrm{D} 3(\mathrm{AAl})$ sub-lineage in the case and control groups.

\begin{tabular}{|c|c|c|c|c|c|}
\hline \multirow{2}{*}{$\begin{array}{l}\text { Genome } \\
\text { position a }\end{array}$} & \multicolumn{2}{|l|}{ Case $(n=4)$} & \multirow{2}{*}{$\begin{array}{l}\text { Amino } \\
\text { acid a }^{\circ}\end{array}$} & \multicolumn{2}{|l|}{ Case $(n=4)$} \\
\hline & Mutation & Frequency (\%) & & Mutation & Frequency (\%) \\
\hline T921C & 4 & 100.0 & T19T & 0 & 0.0 \\
\hline A1041G & 4 & 100.0 & L59L & 0 & 0.0 \\
\hline C1096G & 4 & 100.0 & Q78E & 4 & 100.0 \\
\hline T1139G & 4 & 100.0 & V92G & 4 & 100.0 \\
\hline G1163A & 4 & 100.0 & G100E & 4 & 100.0 \\
\hline T1200C & 4 & 100.0 & A112A & 0 & 0.0 \\
\hline T1366A & 4 & 100.0 & C168S & 4 & 100.0 \\
\hline C1377T & 4 & 100.0 & Y171Y & 0 & 0.0 \\
\hline C1426G & 4 & 100.0 & Q188E & 4 & 100.0 \\
\hline T1486C & 4 & 100.0 & L208L & 0 & 0.0 \\
\hline T1522A & 4 & 100.0 & S220T & 4 & 100.0 \\
\hline C1624T & 4 & 100.0 & L154L & 0 & 0.0 \\
\hline A1668G & 4 & 100.0 & A268A & 0 & 0.0 \\
\hline C1744A & 4 & 100.0 & L294M & 4 & 100.0 \\
\hline A1842G & 4 & 100.0 & $\mathrm{I} 326 \mathrm{M}$ & 4 & 100.0 \\
\hline C2041T & 4 & 100.0 & L393L & 0 & 0.0 \\
\hline G2220C & 4 & 100.0 & E452D & 4 & 100.0 \\
\hline C2237G & 4 & 100.0 & T458S & 4 & 100.0 \\
\hline G2249A & 4 & 100.0 & R462K & 4 & 100.0 \\
\hline T2254C & 4 & 100.0 & L464L & 0 & 0.0 \\
\hline $\mathrm{C} 2262 \mathrm{~T}$ & 4 & 100.0 & G466G & 0 & 0.0 \\
\hline C2287T & 4 & 100.0 & L475L & 0 & 0.0 \\
\hline T2343C & 4 & 100.0 & F493F & 0 & 0.0 \\
\hline C2344T & 4 & 100.0 & L494L & 0 & 0.0 \\
\hline $\mathrm{T} 2586 \mathrm{C}$ & 4 & 100.0 & S574S & 0 & 0.0 \\
\hline A2608C & 4 & 100.0 & R582R & 0 & 0.0 \\
\hline T2631A & 4 & 100.0 & P589P & 0 & 0.0 \\
\hline G2650A & 4 & 100.0 & E596K & 4 & 100.0 \\
\hline
\end{tabular}

a The reference HPV16 E1 sequence used was K02718.
Recently, an international study showed that the differential distribution of HPV16 sub-lineages played key roles in the development of cervical cancer [24-29]. In 2014, Tsakogiannis et al. reported that the HPV16 E1 ORF alone can be used to correctly classify the HPV genome into the major sub-lineages [14], so we identified the distributions of different variants in samples from the case and control groups by constructing phylogenetic trees with the HPV16 E1 sequences, and we found that there was different in the distribution of the HPV16 variants between the case group and control group $(P=0.045)$ and that the D3 (AA1) sub-lineage was found only in the case group. Many previous studies showed that HPV16 D2 and D3 (AA) sub-lineages appear to be more oncogenic than other sub-lineages, which might contribute to the high incidence of cervical cancer [21, 26, 28-33]. In the present study, we observed twenty-seven mutations that had significantly different distributions between the case and control groups. Among these mutations, twenty-two occurred only in the D3 (AA1) sub-lineage. This result also indicated that the D3 (AA1) sub-lineage could be more carcinogenic than the other variants and could play an important role in the development of cervical cancer.

In 1993, Yang et al. reported that the bovine papilloma virus (BPV) E1 protein acts as an 
ATP-dependent DNA helicase and plays a central role in efficient DNA replication in papillomaviruses [34]. Given the high degree of homology of El proteins among the papillomaviruses, the HPV E1 protein was deemed to have a function similar to that of BPV E1 and further study also confirmed this hypothesis [12, 35, 36]. Furthermore, previous reported that the HPV31 E1 protein can be divided into three functional segments: an N-terminal regulatory region that is essential for optimal replication in vivo, the DNA-binding domain that recognizes specific sites in the origin of replication, and a C-terminal enzymatic domain sufficient for self-assembly into hexamers that display ATPase activity and are capable of unwinding short DNA duplexes [12, 37]. Among the mutations with statistically significant differences in distribution between the case and control groups in the current study, the T921C (T19T), T933A (A23A), T1014G (D50E), A1041G (L59L), C1096G (Q78E), G1163A (G100E) and T1200C (A112A) mutations are located in the N-terminal region; the T1366A (C168S), C1426G (Q188E), T1486C (L208L), T1522A (S220T), C1624T (L154L), A1668G (A268A) and C1744A (L294M) mutations are located in the DNA-binding domain; and the C2041T (L393L), G2160A (R432R), G2220C (E452D), T2232C (F456F), C2237G (T458S), G2249A (R462K), C2262T (G466G), C2287T (L475L), A2547G (P561P), T2586C (S574S), A2608C (R582R), T2631A (P589P) and G2650A (E596K) mutations are located in the C-terminal enzymatic domain. These mutations, especially non-synonymous mutations, in different domains may cause functional differences in each functional segment, consequently affecting the roles of $\mathrm{E} 1$ in the development of cervical cancer.

In 2014, Tsakogiannis et al. reported that the A1668G (A268A), G2073A (K403K), T2169C (D435D), T2189C (I442T), A2453T (N530I), C2454T (N530N), A2587T (R575W) and G2650A (E596K) mutations of HPV16 E1 were identified only in high-grade dysplasia cases in a Greek population [18]. In the current study, we also found that A1668G (A268A) and G2650A (E596K) occurred only in the case group, and this finding suggested these two mutations may play key roles in the carcinogenesis of cervical cancer. Furthermore, our results showed that the T921C (T19T), T933A (A23A), T1014G (D50E), A1041G (L59L), C1096G (Q78E), G1163A (G100E), T1200C (A112A), T1366A (C168S), T1407G (S181R), C1426G (Q188E), T1486C (L208L), T1522A (S220T), C1624T (L154L), C1744A (L294M), C2041T (L393L), G2220C (E452D), T2232C (F456F), C2237G (T458S), G2249A (R462K), C2262T (G466G), C2287T (L475L), T2567G (I568S), T2586C (S574S), A2608C (R582R) and T2631A (P589P) mutations were also found only in the case group, however, these mutations were not found in the study by Tsakogiannis et al., but they found the G2073A (K403K), T2169C (D435D), T2189C (I442T), A2453T (N530I), C2454T (N530N) and A2587T (R575W) mutations in the high-grade dysplasia cases, which were not found in our study. Genetic differences between different populations leading to the generation of different mutations in the viral genome during coevolution and the difference in sample sizes may both be partly responsible for the disparity between these studies.

By comparing the mutations in the different variants of HPV16 in this study, we found eight mutations only in the A4 (As) sub-lineage, seventeen mutations only in the A1-A3 (EUR) sub-lineage, and twenty-two mutations only in the D3 (AA1) sub-lineage. Thus, these characteristic E1 mutations can be specific to each sub-lineage. Moreover, we found consistent mutations in the HPV16 sequences were present in different variants too. Furthermore, we found that T933A (A23A), T1014G (D50E), and G2160A (R432R) showed a significant difference in distribution between the case and control groups for the A4 (As) sub-lineage and that T2232C (F456F), G2337A (M491I), and A2547G(P561P) had a statistically significant difference in distribution between the case group and control group for the A1-A3 (EUR) sub-lineage; thus, these mutations could play different roles in the A4 (As) sub-lineage and A1-A3 (EUR) sub-lineage.

The integration of HPV16 genome into the host chromosome at an early stage of the viral life cycle plays a major role in the pathogenesis of cervical cancer, and the integration of the virus usually disrupts the E1 and/or E2 open reading frames (ORFs), which causes transcriptional activation of the viral oncogenes E6 and E7. Therefore, the disruption of the E1 and E2 ORFs is associated with the progression of cervical intraepithelial neoplasia to invasive cancer[38]. Furthermore, Filho et al. reported that the disruption of HPV16 E1 or E2 genes could alter HPV expression by affecting the methylation of 3'LCR in 215 [39]. However, in 2017, Cricca et al. reported $E 2$ gene could be a more suitable target than E1 to identify integration into host genome in high-grade cervical lesions [40]. Thus, we just focused on the relationship between the mutations of E1 gene and cervical cancer development not the disruption. However, this could be one of the limitations in the current study.

In the present study, we showed that the D3 (AA1) sub-lineage was highly associated with cervical cancer compared with other variants. Moreover, we found that the T933A (A23A), T1014G (D50E), and G2160A (R432R) mutations in the A4 (As) sub-lineage and the T2232C (F456F), G2337A (M491I), and 
A2547G (P561P) mutations in the A1-A3 (EUR) sub-lineage played important roles in the development of cervical cancer.

\section{Abbreviations}

HPV16: human papillomavirus type 16; LCR: long control region; EUR: European; As: Asian; NA: North American; AA1: Asian-American 1; AA2: Asian-American 2; AFR1: African-1; AFR2: African-2; ORF: open reading frame.

\section{Supplementary Material}

Supplementary figures and tables.

http://www.medsci.org/v16p1042s1.pdf

\section{Acknowledgement}

This work was supported by grants from the National Science Foundation of China (81573206 and 31270030), Yunnan Applied Basic Research Projects (2016FA034), Fundamental Research Funds for the Central Universities and the PUMC Youth Fund (3332015149), The Association Foundation Program of Yunnan Provincial Science and Technology Department and Kunming Medical University (2017FE467-077 and 2017FE467-012), Foundation Program of the Yunnan Province (No. 2017NS189). and Special Funds for high-level health talents of Yunnan Province (D-201669 and L-201615). The funders had no role in study design, data collection and analysis, decision to publish or preparation of the manuscript.

\section{Ethical approval}

This study was approved by the Institutional Review Boards of the 3rd Affiliated Hospital of Kunming Medical University, and the protocol was in accordance with the Declaration of Helsinki. All patients provided written informed consent.

\section{Competing Interests}

The authors have declared that no competing interest exists.

\section{References}

1. Schiffman M, Castle PE, Jeronimo J, Rodriguez AC, Wacholder S. Human papillomavirus and cervical cancer. Lancet. 2007; 370: 890-907.

2. Petry KU. HPV and cervical cancer. Scandinavian journal of clinical and laboratory investigation Supplementum. 2014; 244: 59-62; discussion

3. Flores-Diaz E, Sereday KA, Ferreira S, Sirak B, Sobrinho JS, Baggio ML, et al. HPV-6 Molecular Variants Association With the Development of Genital Warts in Men: The HIM Study. J Infect Dis. 2017; 215: 559-65.

4. Measso do Bonfim C, Simao Sobrinho J, Lacerda Nogueira R, Salgado Kupper D, Cardoso Pereira Valera F, Lacerda Nogueira M, et al. Differences in Transcriptional Activity of Human Papillomavirus Type 6 Molecular Variants in Recurrent Respiratory Papillomatosis. PLoS One. 2015; 10: e0132325.

5. Flores-Diaz E, Sereday KA, Ferreira S, Sirak B, Sobrinho JS, Baggio ML, et al. HPV-11 variability, persistence and progression to genital warts in men: the HIM study. J Gen Virol. 2017; 98: 2339-42.

6. Munoz N, Bosch FX, de Sanjose S, Herrero R, Castellsague X, Shah KV, et al. Epidemiologic classification of human papillomavirus types associated with cervical cancer. N Engl J Med. 2003; 348: 518-27.
7. de Sanjose S, Quint WG, Alemany L, Geraets DT, Klaustermeier JE, Lloveras B, et al. Human papillomavirus genotype attribution in invasive cervical cancer: a retrospective cross-sectional worldwide study. The Lancet Oncology. 2010; 11: 1048-56.

8. Cho HW, So KA, Lee JK, Hong JH. Type-specific persistence or regression of human papillomavirus genotypes in women with cervical intraepithelial neoplasia 1: A prospective cohort study. Obstet Gynecol Sci. 2015; 58: 40-5.

9. Betiol JC, Sichero L, Costa HOO, de Matos LL, Andreoli MA, Ferreira S, et al. Prevalence of human papillomavirus types and variants and p16(INK4a) expression in head and neck squamous cells carcinomas in Sao Paulo, Brazil. Infect Agent Cancer. 2016; 11: 20.

10. Kreimer AR, Clifford GM, Boyle P, Franceschi S. Human papillomavirus types in head and neck squamous cell carcinomas worldwide: a systematic review. Cancer Epidemiol Biomarkers Prev. 2005; 14: 467-75.

11. Burk RD, Chen Z, Van Doorslaer K. Human papillomaviruses: genetic basis of carcinogenicity. Public Health Genomics. 2009; 12: 281-90.

12. Bergvall M, Melendy T, Archambault J. The E1 proteins. Virology. 2013; 445: 35-56.

13. Conger KL, Liu JS, Kuo SR, Chow LT, Wang TS. Human papillomavirus DNA replication. Interactions between the viral E1 protein and two subunits of human dna polymerase alpha/primase. J Biol Chem. 1999; 274: 2696-705.

14. Tsakogiannis D, Darmis F, Gortsilas P, Ruether IG, Kyriakopoulou Z, Dimitriou TG, et al. Nucleotide polymorphisms of the human papillomavirus 16 E1 gene. Archives of virology. 2014; 159: 51-63.

15. Clower RV, Fisk JC, Melendy T. Papillomavirus E1 protein binds to and stimulates human topoisomerase I. J Virol. 2006; 80: 1584-7.

16. Loo YM, Melendy T. Recruitment of replication protein A by the papillomavirus E1 protein and modulation by single-stranded DNA. J Virol. 2004; 78: 1605-15.

17. Baedyananda F, Chaiwongkot A, Bhattarakosol P. Elevated HPV16 E1 Expression Is Associated with Cervical Cancer Progression. Intervirology. 2017; 60: 171-80.

18. Tsakogiannis D, Kyriakopoulou Z, Amoutzias G, Ruether IGA, Dimitriou TG, Panotopoulou E, et al. Identification of novel E6-E7 sequence variants of human papillomavirus 16. Archives of virology. 2013; 158: 821-8.

19. Tsakogiannis D, Ruether IGA, Kyriakopoulou Z, Pliaka V, Theoharopoulou A, Skordas V, et al. Sequence variation analysis of the E2 gene of human papilloma virus type 16 in cervical lesions from women in Greece. Archives of virology. 2012; 157: 825-32.

20. Tsakogiannis D, Ruether IGA, Kyriakopoulou Z, Pliaka V, Skordas V, Gartzonika C, et al. Molecular and phylogenetic analysis of the HPV 16 E4 gene in cervical lesions from women in Greece. Archives of virology. 2012; 157; 1729-39.

21. Dai S, Yao Y, Yan Z, Zhou Z, Shi L, Wang X, et al. The association of human papillomavirus type 16 E2 variations with cervical cancer in a Han Chinese population. Infect Genet Evol. 2018; 64: 241-8.

22. Li WJ, Xu HX, Chen $\mathrm{ZH}, \mathrm{Xu}$ WD, Wu YJ. Characteristics of carcinogenic human papillomavirus infection in Suzhou: Epidemiology, vaccine evaluation, and associated diseases. Journal of medical virology. 2017; 89: 895-901.

23. Castillo A, Wang L, Koriyama C, Eizuru Y, Jordan K, Akiba S. A systems biology analysis of the changes in gene expression via silencing of HPV-18 E1 expression in HeLa cells. Open biology. 2014; 4.

24. Cornet I, Gheit T, Iannacone MR, Vignat J, Sylla BS, Del Mistro A, et al. HPV16 genetic variation and the development of cervical cancer worldwide. Br J Cancer. 2013; 108: 240-4.

25. Smith B, Chen Z, Reimers L, van Doorslaer K, Schiffman M, Desalle R, et al. Sequence imputation of HPV16 genomes for genetic association studies. PLoS One. 2011; 6: e21375.

26. Schiffman M, Rodriguez AC, Chen Z, Wacholder S, Herrero R, Hildesheim A, et al. A population-based prospective study of carcinogenic human papillomavirus variant lineages, viral persistence, and cervical neoplasia. Cancer Res. 2010; 70: 3159-69.

27. Chan PK, Lam CW, Cheung TH, Li WW, Lo KW, Chan MY, et al. Human papillomavirus type 16 intratypic variant infection and risk for cervical neoplasia in southern China. J Infect Dis. 2002; 186: 696-700.

28. Jackson R, Rosa BA, Lameiras S, Cuninghame S, Bernard J, Floriano WB, et al. Functional variants of human papillomavirus type 16 demonstrate host genome integration and transcriptional alterations corresponding to their unique cancer epidemiology. BMC Genomics. 2016; 17: 851.

29. Niccoli S, Abraham S, Richard C, Zehbe I. The Asian-American E6 variant protein of human papillomavirus 16 alone is sufficient to promote immortalization, transformation, and migration of primary human foreskin keratinocytes. J Virol. 2012; 86: 12384-96.

30. Berumen J, Ordonez RM, Lazcano E, Salmeron J, Galvan SC, Estrada RA, et al. Asian-American variants of human papillomavirus 16 and risk for cervical cancer: a case-control study. Journal of the National Cancer Institute. 2001; 93: 1325-30.

31. Quint KD, de Koning MN, van Doorn LJ, Quint WG, Pirog EC. HPV genotyping and HPV16 variant analysis in glandular and squamous neoplastic lesions of the uterine cervix. Gynecol Oncol. 2010; 117: 297-301.

32. Tornesello ML, Losito S, Benincasa G, Fulciniti F, Botti G, Greggi S, et al. Human papillomavirus (HPV) genotypes and HPV16 variants and risk of adenocarcinoma and squamous cell carcinoma of the cervix. Gynecol Oncol. 2011; 121: 32-42 
33. Villa LL, Sichero L, Rahal P, Caballero O, Ferenczy A, Rohan T, et al. Molecular variants of human papillomavirus types 16 and 18 preferentially associated with cervical neoplasia. J Gen Virol. 2000; 81: 2959-68.

34. Yang L, Mohr I, Fouts E, Lim DA, Nohaile M, Botchan M. The E1 protein of bovine papilloma virus 1 is an ATP-dependent DNA helicase. Proc Natl Acad Sci U S A. 1993; 90: 5086-90.

35. Bream GL, Ohmstede CA, Phelps WC Characterization of human papillomavirus type $11 \mathrm{E} 1$ and E2 proteins expressed in insect cells. J Virol. 1993; 67: 2655-63.

36. Hughes FJ, Romanos MA. E1 protein of human papillomavirus is a DNA helicase/ATPase. Nucleic Acids Res. 1993; 21: 5817-23.

37. Morin G, Fradet-Turcotte A, Di Lello P, Bergeron-Labrecque F, Omichinski JG, Archambault J. A conserved amphipathic helix in the N-terminal regulatory region of the papillomavirus E1 helicase is required for efficient viral DNA replication. J Virol. 2011; 85: 5287-300.

38. Tsakogiannis D, Gortsilas P, Kyriakopoulou Z, Ruether IG, Dimitriou TG, Orfanoudakis G, et al. Sites of disruption within E1 and E2 genes of HPV16 and association with cervical dysplasia. Journal of medical virology. 2015; 87: 1973-80.

39. Filho SMA, Bertoni N, Brant AC, Vidal JPCB, Felix SP, Cavalcanti SMB, et al. Methylation at 3'LCR of HPV16 can be affected by patient age and disruption of E1 or E2 genes. Virus research. 2017; 232: 48-53.

40. Cricca M, Venturoli S, Leo E, Costa S, Musiani M, Zerbini M. Disruption of HPV 16 E1 and E2 genes in precancerous cervical lesions. Journal of Virological Methods. 2009; 158: 180-3 